\title{
The relationship between exposure to polycyclic aromatic hydrocarbons and adult atopic dermatitis
}

\author{
Kuo-Tung Tang, ${ }^{1,2}$ Pin-An Chen, ${ }^{3}$ Maw-Rong Lee, ${ }^{3}$ Mey-Fann Lee, ${ }^{4}$ Yi-Hsing Chen ${ }^{1,2}$
}

\begin{abstract}
Background: Polycyclic aromatic hydrocarbons are one of the major pathogenic components in air pollution. Previous studies have demonstrated an association between air pollution and atopic dermatitis.
\end{abstract}

Objective: We sought to explore the relationship between polycyclic aromatic hydrocarbons exposure and adult atopic dermatitis.

Methods: We prospectively recruited 23 adult patients with atopic dermatitis and 11 healthy controls. Plasma levels of inflammatory cytokines were determined using enzyme-linked immunosorbent assay. Expression levels of aryl hydrocarbon receptor, which mediates the effect of polycyclic aromatic hydrocarbons, and cytokines in peripheral blood nuclear cells (PBMCs) were measured using reverse transcription polymerase chain reaction. Urine levels of 16 polycyclic aromatic hydrocarbon metabolites were determined by gas chromatography- tandem mass spectrometry.

Results: Patients with atopic dermatitis had lower levels of interleukin (IL)-5 and IL-23, and lower PBMC messenger RNA expression levels of interferon- $\gamma$ than the healthy controls. Plasma levels of IL-22 were moderately and positively associated with the SCORAD index. Creatinine-corrected urine levels of 9-hydroxyfluorene and 2-hydroxyphenanthrene were elevated in the atopic dermatitis group. However the difference was not statistically significant after Bonferroni correction.

Conclusion: Our results demonstrated that the polycyclic aromatic hydrocarbons fluorene and phenanthrene are potentially associated with the pathogenesis of atopic dermatitis in adults.

Key words: air pollution; atopic dermatitis; fluorine; phenanthrene; polycyclic aromatic hydrocarbon

From:

${ }^{1}$ Division of Allergy, Immunology and Rheumatology,

Taichung Veterans General Hospital, Taichung, Taiwan

${ }^{2}$ School of Medicine, National Yang-Ming University, Taipei, Taiwan

${ }^{3}$ Department of Chemistry, National Chung-Hsing University,

Taichung, Taiwan

${ }^{4}$ Department of Medical Research, Taichung Veterans General Hospital, Taichung, Taiwan

Corresponding author:

Yi-Hsing Chen

Division of Allergy, Immunology and Rheumatology,

Taichung Veterans General Hospital, No. 1650, Sec. 4, Taiwan Blvd.,

Taichung 40705, Taiwan

E-mail: ysanne@vghtc.gov.tw

Abbreviations:

$\mathrm{AD} \quad$ atopic dermatitis

AhR aryl hydrocarbon receptor

GAPDH glyceraldehyde-3-phosphate dehydrogenase

IFN interferon

IL interleukin

LOD limit of detection
MGCB magnetic graphitized carbon black

mRNA messenger RNA

$\mathrm{PAH} \quad$ polycyclic aromatic hydrocarbon

PBMC peripheral blood mononuclear cell

PCR polymerase chain reaction

TNF tumor necrosis factor

\section{Introduction}

Polycyclic aromatic hydrocarbons (PAHs) originate from incomplete combustion of organic materials such as automobile exhaust, fossil fuels, tobacco, and industrial activities. They are recognized as being one of the major pathogenic components in ambient air pollution, and have been implicated in the provocation of an allergic response. ${ }^{1,2}$ It has been speculated that PAHs may exert biological effects through the binding of aryl hydrocarbon receptor (AhR). ${ }^{3}$ Upon binding of ligands, AhR undergoes conformational changes that expose a nuclear translocation site. AhR then translocates to the nucleus and initiate transcription of genes with promoters 
containing a dioxin-responsive element sequence. Interestingly, AhR has been shown to be involved in the elicitation of an allergic response. ${ }^{4,5}$ Some studies have also indicated that AhR is highly expressed in patients with allergic diseases such as allergic rhinitis, asthma and atopic dermatitis (AD). ${ }^{6-8}$

Air pollution has been proposed to be an important contributing factor in allergic diseases, ${ }^{9}$ and an association between air pollution and $\mathrm{AD}$ has been demonstrated in children ${ }^{10}$ and adults. ${ }^{11}$ We hypothesized that PAH exposure may be associated with $\mathrm{AD}$ in adults. To test this hypothesis, we determined $\mathrm{PAH}$ exposure in adult $\mathrm{AD}$ patients based on their metabolite concentrations in urine, and explored the relationship between $\mathrm{PAH}$ exposure and $\mathrm{AD}$.

\section{Methods \\ Patients}

We prospectively enrolled consecutive 23 adult $(\geq 20$ years) AD outpatients from October 2016 through April 2017. $\mathrm{AD}$ was diagnosed based on the 1980 Hanifin and Rajka criteria. ${ }^{12}$ Eleven healthy controls (HCs) without allergic diseases (allergic rhinitis, asthma or atopic dermatitis) and with a negative skin prick test to major allergens including Der $p$, Der $f$, and extracts of American cockroach, ${ }^{13}$ a biting midge Forcipomyia taiwana, ${ }^{14}$ Cladosporium oxysporum, Cladosporium cladosporioides and Penicillium brevicompactum were simultaneously recruited. The study protocol was approved by the Institutional Review Board of Taichung Veterans General Hospital (IRB TCVGH NO: CE16097A) and the written consent of all participants was obtained according to the Declaration of Helsinki.

\section{Determination of clinical parameters}

Patient characteristics were recorded. Serum total IgE report within 3 months was obtained in 19 patients. It was measured using a fluorescent enzyme immunoassay (ImmunoCAP-FEIA, Phadia, Freiburg, Germany), with an analytical range of 2-5000 IU/ml and the normal range of $<100 \mathrm{IU} /$ $\mathrm{ml}$. If the total IgE value was beyond the analytical range, the upper or lower bound of the range was used in the analysis instead. Disease severity of $\mathrm{AD}$ was determined according to the SCORing AD (SCORAD) index. ${ }^{15}$

\section{Determination of immunological parameters}

Whole blood $20 \mathrm{ml}$ was collected for each study subject. Plasma levels of inflammatory cytokines including interferon (IFN)- $\gamma$, interleukin (IL)-5, IL-17A, IL-22 and IL-23 were determined using enzyme-linked immunosorbent assay kits (Quantikine $^{\mathrm{TM}}, \mathrm{R} \& \mathrm{D}$ Systems, Abingdon, UK), and plasma levels of tumor necrosis factor (TNF)- $\alpha$ and IL- 4 was determined using High Sensitivity ELISA kits (Quantikine ${ }^{\mathrm{TM}} \mathrm{HS}$, R\&D Systems, Abingdon, UK), in duplicates according to manufacturer's instructions. Optical densities were measured at $450 \mathrm{~nm}$ for TNF- $\alpha$, IFN- $\gamma$, IL-5, IL-17A, IL-22 and IL-23, and at $490 \mathrm{~nm}$ for IL-4, using a Thermo Multiskan EX Microplate Photometer (Thermo Fisher Scientific Inc.). The detection limits were $0.5 \mathrm{pg} / \mathrm{ml}$ for TNF- $\alpha, 12.5 \mathrm{pg} / \mathrm{ml}$ for IFN- $\gamma, 0.22 \mathrm{pg} / \mathrm{ml}$ for IL-4, $1.08 \mathrm{pg} / \mathrm{ml}$ for IL-5, $15 \mathrm{pg} / \mathrm{ml}$ for IL-17A, $5.8 \mathrm{pg} / \mathrm{ml}$ for IL-22 and $16.3 \mathrm{pg} / \mathrm{ml}$ for IL-23. Values below the detection limit were not analyzed. Peripheral blood mononuclear cells (PBMCs) were isolated based on FicollPaque ${ }^{\circledast}$ density gradient centrifugation. Messenger RNA (mRNA) expression levels of AhR and inflammatory cytokines in PBMCs were determined by polymerase chain reaction (PCR). Briefly, total RNA was acquired from PBMCs using Trizol reagent (Sigma, St. Louis, MO). RNA aliquots were then reverse transcribed using an $A B$ High-Capacity cDNA Archive Kit (Applied Biosystems or AB, Waltham, MA). Expression levels of individual genes were measured in duplicate using Taqman Gene Expression Assays (AB) with the StepOne Real-Time PCR (AB). Primers for AhR (assay ID Hs00169233_m1), IFN- $\gamma$ (ID Hs00989291_m1), and IL17A (ID Hs00174383_m1) were used in the experiments. For standardization, expression levels of the housekeeping gene glyceraldehyde-3-phosphate dehydrogenase (GAPDH) were determined in parallel for each sample. All amplification reactions were carried out for 40 cycles, and the obtained data were normalized against the expression levels of GAPDH. The relative expression level of each target gene was calculated based on the comparative threshold cycle $(\mathrm{Ct})$ method: $2^{-\Delta \mathrm{Ct}}$, in which $\Delta \mathrm{Ct}=$ sample $\mathrm{Ct}_{\text {target gene }}-$ sample $\mathrm{Ct}_{\mathrm{GAPDH}}$.

\section{Determination of urine PAH metabolites}

First-voided morning urine $(10 \mathrm{ml})$ was collected from each study participant. Each urine sample was analyzed for a total of 16 major PAH metabolites: ${ }^{16,17}$ naphthalene metabolites (1-hydroxynaphthalene and 2-hydroxynaphthalene), fluorene metabolites (2-hydroxyfluorene, 3-hydroxyfluorene, and 9-hydroxyfluorene), phenanthrene metabolites (1-hydroxyphenanthrene, 2-hydroxyphenanthrene, 3-hydroxyphenanthrene, 4-hydroxyphenanthrene, and 9-hydroxyphenanthrene), pyrene metabolite (1-hydroxypyrene), benzo(a) anthracene metabolite (9-hydroxybenz(a)anthracene), and chrysene metabolites (2-hydroxychrysene, 3-hydroxychrysene, 4-hydroxychrysene, and 6-hydroxychrysene). The sample first underwent enzymatic deconjugation by $\beta$-glucuronidase. As a simple and quick method while maintaining a low limit of detection (LOD), ${ }^{18}$ we oxidized DisQuE ${ }^{\mathrm{TM}}$ (graphitized carbon black) (Waters Corp., Milford, MA) nanoparticles using nitric acid. We then generated magnetic graphitized carbon black (MGCB) by mixing $50 \mathrm{mg}$ oxidized graphitized carbon black, $810 \mathrm{mg} \mathrm{FeCl} \cdot 6 \mathrm{H}_{2} \mathrm{O}, 170 \mathrm{mg}$ sodium citrate dehydrate, $3600 \mathrm{mg}$ sodium acetate anhydrous, and $1000 \mathrm{~g}$ polyethylene glycol in $40 \mathrm{ml}$ ethylene glycol. After ultrasonication for $3 \mathrm{~h}$, the mixture was poured into a $125-\mathrm{ml}$ autoclave and placed in a gas chromatography oven at $200^{\circ} \mathrm{C}$ for $10 \mathrm{~h}$. After repeated washes with ultrapure water and ethanol, MGCB was dried for $10 \mathrm{~h}$ at $60^{\circ} \mathrm{C}$ in a vacuum oven and dissolved in ultrapure water for the following experiments. We used $10 \mathrm{mg} / \mathrm{ml} \mathrm{MGCB}$ solution to extract urine PAH metabolites. Quantification was performed using a TSQ 9000 Triple Quadrupole Gas Chromatography-Tandem Mass Spectrometry System (Thermo Scientific, San Jose, CA). The LOD was defined as three times the standard deviation of blanks. Values below the LOD were excluded from the analysis. We previously demonstrated that the recoveries of these compounds using this method were in the range of $86.4-119.7 \%$, and the LODs were in the range of $0.2-59 \mathrm{pg} / \mathrm{ml}$ (Table S1). To control for dilution of the urine, urine creatinine was measured using the Jaffé method 
(Advia 1800; Siemens, New York, NY). Creatinine-corrected $\mathrm{PAH}$ concentrations were used in the final analysis.

\section{Statistical analysis}

Statistical analyses were performed using Stata software 15.0 (StataCorp, College Station, TX). Visual inspection of quantile-quantile plots determined that none of the variables in the analysis were normally distributed. Quantitative data were presented as medians plus the interquartile range. The Mann-Whitney U test was used for between-group comparisons. Correlation analysis between serum IgE and the SCORAD index, and immunological parameters and urine levels of $\mathrm{PAH}$ metabolites in the $\mathrm{AD}$ patients were performed using the non-parametric Spearman's correlation test in 1000 bootstrap samples. Two-tailed $p$ values $<0.003$ were regarded to be statistically significant after Bonferroni correction for multiple comparisons with regards to the $16 \mathrm{PAH}$ metabolites.

\section{Results}

Baseline characteristics of the adult AD patients and HCs

The baseline characteristics of the adult AD patients and HCs are illustrated in Table 1. The median age of the adult $\mathrm{AD}$ patients was 34 years, which was older than the HCs $(24$ years). The median serum total IgE level was $582 \mathrm{IU} / \mathrm{ml}$, and the median SCORAD index was 20.9 in the AD patients. Fifteen $(65 \%)$ of them took systemic immunomodulators. Half of the patient took oral corticosteroids and one third of them took methotrexate.

Table 1. Baseline characteristics of the study participants.

\begin{tabular}{|lcc|}
\hline & $\begin{array}{c}\text { AD patients } \\
(\mathbf{n}=\mathbf{2 3})\end{array}$ & $\begin{array}{c}\text { HCs } \\
(\mathbf{n}=\mathbf{1 1})\end{array}$ \\
\hline Age, median (IQR) & $34(29,43)$ & $24(20,34)$ \\
\hline Female & $10(43 \%)$ & $7(64 \%)$ \\
\hline Allergic rhinitis & $10(43 \%)$ & $0(0 \%)$ \\
\hline Asthma & $6(26 \%)$ & $0(0 \%)$ \\
\hline Smoking & $5(22 \%)$ & $2(18 \%)$ \\
\hline Serum total IgE (IU/ml) & $582(171,3945)$ & NA \\
\hline SCORAD index & $20.9(11.4,35.1)$ & NA \\
\hline Systemic immunomodulators & $12(52 \%)$ & NA \\
\hline Oral corticosteroids & $3(13 \%)$ & NA \\
\hline Azathioprine & $3(13 \%)$ & NA \\
\hline Cyclosporine & $7(30 \%)$ & NA \\
\hline Methotrexate & $2(9 \%)$ & NA \\
\hline Omalizumab &
\end{tabular}

$\mathrm{AD}$, atopic dermatitis; HC, healthy control; NA, not available; IQR, interquartile range.
Comparisons of immunological parameters between the adult AD patients and HCs

As regards to the measurement of plasma cytokine levels, there were more than half of the values below detection limits for IFN- $\gamma$, IL- 4 and IL-17A, and these cytokines were not analyzed. In addition, there were one sample IL-22 value, 2 sample IL- 5 values, and 6 sample IL-23 values below detection limits. The $\mathrm{Ct}$ values for PBMC expression levels of IL-17A were around 35 and not analyzed. As demonstrated in Table 2, our exploratory analysis showed that the AD patients had lower plasma levels of IL-5 and IL-23, and lower expression levels of IFN- $\gamma$ in PBMCs, than the HCs.

Table 2. Comparisons of immunological parameters and urine PAH metabolites between the AD patients and HCs.

\begin{tabular}{|c|c|c|}
\hline & $\begin{array}{l}\text { AD patients } \\
\qquad(\mathbf{n}=23)\end{array}$ & $\begin{array}{c}\text { HCs } \\
(\mathrm{n}=11)\end{array}$ \\
\hline \multicolumn{3}{|c|}{ Plasma levels of cytokines, median (IQR) (pg/ml) } \\
\hline Tumor necrosis factor- $\alpha$ & $\begin{array}{c}1.02 \\
(0.72,1.30)\end{array}$ & $\begin{array}{c}0.89 \\
(0.83,1.06)\end{array}$ \\
\hline Interluekin-5 & $\begin{array}{c}3.86 \\
(3.28,4.59)\end{array}$ & $\begin{array}{c}4.70 \\
(3.91,6.14)^{\star}\end{array}$ \\
\hline Interleukin-22 & $\begin{array}{c}48.57 \\
(33.74,60.95)\end{array}$ & $\begin{array}{c}40.85 \\
(19.22,55.01)\end{array}$ \\
\hline Interluekin-23 & $\begin{array}{c}60.34 \\
(46.57,77.12)\end{array}$ & $\begin{array}{c}91.83 \\
(53.34,131.44)^{*}\end{array}$ \\
\hline
\end{tabular}

mRNA expression levels in PBMCs, median $(\mathrm{IQR})^{\dagger}$

$\begin{array}{lcc}\text { Aryl hydrocarbon receptor } & 0.009 & 0.010 \\ & (0.008,0.013) & (0.007,0.014) \\ & 1.4 \times 10^{-4} & 3.0 \times 10^{-4} \\ \text { Interferon- } \gamma & \left(0.6 \times 10^{-4},\right. & \left(1.2 \times 10^{-4}\right. \\ & \left.2.1 \times 10^{-4}\right) & \left.4.1 \times 10^{-4}\right)^{*}\end{array}$

Urine levels of PAH metabolites, median (IQR) (ug/g)*

\begin{tabular}{lll} 
1-hydroxynaphthalene & $1.20(0.38,2.69)$ & $0.46(0.28,2.84)$ \\
2-hydroxynaphthalene & $0.88(0.33,2.00)$ & $0.61(0.32,1.00)$ \\
2-hydroxyfluorene & $0.07(0.03,0.14)$ & $0.04(0.02,0.05)$ \\
3-hydroxyfluorene & $0.05(0.03,0.12)$ & $0.03(0.01,0.07)$ \\
9-hydroxyfluorene & $0.09(0.04,0.17)$ & $0.05(0.02,0.09)^{*}$ \\
1-hydroxyphenanthrene & $0.07(0.03,0.11)$ & $0.05(0.02,0.07)$ \\
2-hydroxyphenanthrene & $0.04(0.02,0.07)$ & $0.02(0.02,0.03)^{\star}$ \\
3-hydroxyphenanthrene & $0.05(0.03,0.08)$ & $0.03(0.02,0.06)$ \\
4-hydroxyphenanthrene & $0.01(0.01,0.01)$ & $0.00(0.00,0.01)$ \\
1-hydroxypyrene & $0.06(0.03,0.14)$ & $0.04(0.03,0.05)$ \\
\hline
\end{tabular}

$\mathrm{AD}$, atopic dermatitis; $\mathrm{HC}$, healthy control; $\mathrm{PAH}$, polyaromatic hydrocarbons; PBMCs, peripheral blood mononuclear cells; IQR, interquartile range

† Relative mRNA expression levels $\left(2^{-\Delta \mathrm{Ct}}\right)$ normalized to glyceraldehyde

3-phosphate dehydrogenase (GAPDH) mRNA.

* Creatinine-corrected.

${ }^{*} p<0.05$. 
Comparisons of urine PAH metabolites between the adult $A D$ patients and $\mathrm{HCs}$

Table 2 demonstrates creatinine-corrected urine levels of $\mathrm{PAH}$ metabolites in the $\mathrm{AD}$ patients and HCs. There were seven values below the LOD with respect to 2-hydroxynaphthalene, one value below the LOD with respect to 2-hydroxyfluorene, four values below the LOD with respect to 9-hydroxyfluorene, and one value below the LOD with respect to 1-hydroxyphenanthrene. More than one third of the sample values were below the LOD with respect to 9-hydroxyphenanthrene, 9-hydroxybenz(a)anthracene and all chrysene metabolites, and these compounds were not analyzed. Urine levels of 9-hydroxyfluorene and 2-hydroxyphenanthrene were elevated in the AD patients compared to the HCs (Figure 1). However, the statistical significance was lost after correction for multiple comparisons.

\section{(a)}

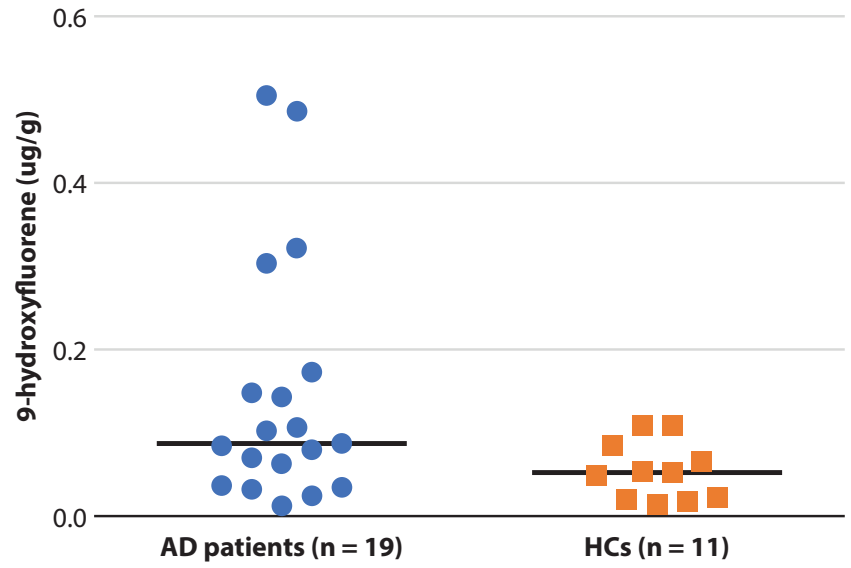

(b)

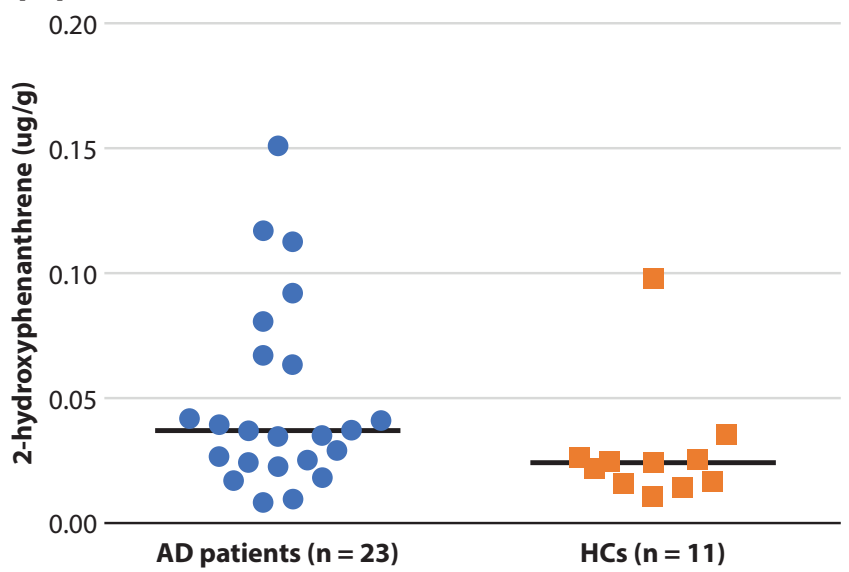

Figure 1. Creatinine-corrected urine levels of (a) 9-hydroxyfluorene and (b) 2-hydroxyphenanthrene in adult AD patients and healthy controls.

$\mathrm{AD}$, atopic dermatitis.

\section{Correlational analyses}

As shown in Table 3, IFN- $\gamma$ mRNA expression levels in the PBMCs were strongly and negatively associated with serum IgE levels; whereas plasma levels of IL-23 were moderately and positively associated with serum IgE levels. The SCORAD index was moderately and positively associated with plasma levels of IL-22.

Table 3. Spearman's correlation coefficients between serum IgE and SCORAD index, and immunological parameters, and urine levels of creatinine-corrected PAH metabolites in $\mathrm{AD}$ patients.

\begin{tabular}{|c|c|c|}
\hline & Serum IgE & $\begin{array}{c}\text { SCORAD } \\
\text { index }\end{array}$ \\
\hline \multicolumn{3}{|l|}{ Plasma levels of cytokines } \\
\hline Tumor necrosis factor- $\alpha$ & $\begin{array}{c}0.25 \\
(-0.20,0.70)\end{array}$ & $\begin{array}{c}0.26 \\
(-0.17,0.69)\end{array}$ \\
\hline Interluekin-5 & $\begin{array}{c}0.12 \\
(-0.33,0.56)\end{array}$ & $\begin{array}{c}0.14 \\
(-0.30,0.59)\end{array}$ \\
\hline Interleukin-22 & $\begin{array}{c}0.24 \\
(-0.31,0.79)\end{array}$ & $\begin{array}{c}0.51 \\
(0.14,0.88)\end{array}$ \\
\hline Interluekin-23 & $\begin{array}{c}0.40 \\
(-0.06,0.86)\end{array}$ & $\begin{array}{c}-0.16 \\
(-0.63,0.30)\end{array}$ \\
\hline \multicolumn{3}{|c|}{ mRNA expression levels in PBMCs ${ }^{\dagger}$} \\
\hline Aryl hydrocarbon receptor & $\begin{array}{c}0.36 \\
(-0.02,0.74)\end{array}$ & $\begin{array}{c}0.28 \\
(-0.10,0.66)\end{array}$ \\
\hline Interferon- $\gamma$ & $\begin{array}{c}-0.74 \\
(-0.97,-0.50)\end{array}$ & $\begin{array}{c}-0.16 \\
(-0.59,0.27)\end{array}$ \\
\hline \multicolumn{3}{|l|}{ Urine levels of PAH metabolites* } \\
\hline 9-hydroxyfluorene & $\begin{array}{c}0.19 \\
(-0.33,0.71)\end{array}$ & $\begin{array}{c}0.13 \\
(-0.41,0.66)\end{array}$ \\
\hline 2-hydroxyphenanthrene & $\begin{array}{c}0.08 \\
(-0.44,0.61)\end{array}$ & $\begin{array}{c}0.02 \\
(-0.43,0.48)\end{array}$ \\
\hline
\end{tabular}

$\mathrm{AD}$, atopic dermatitis; PAH, polyaromatic hydrocarbons; PBMCs, peripheral blood mononuclear cells.

† Relative mRNA expression levels $\left(2^{-\Delta \mathrm{Ct}}\right)$ normalized to glyceraldehyde 3-phosphate dehydrogenase (GAPDH) mRNA.

* Creatinine-corrected.

\section{Discussion}

This study investigated the association between PAH exposure and $\mathrm{AD}$. We found higher urine levels of 9-hydroxyfluorene and 2-hydroxyphenanthrene in the $\mathrm{AD}$ patients compared to the HCs. PAH exposure may play a role in the pathogenesis of AD.

Our adult AD patients were younger than those (44 years) in the general population, as reported in previous studies. ${ }^{11,19}$ Male predominance was noted in our adult $\mathrm{AD}$ patients, which is somewhat different from previous studies. ${ }^{11,19}$ Other atopic diseases including allergic rhinitis and asthma were prevalent in our $\mathrm{AD}$ patients, which is compatible with a previous report. ${ }^{11}$ Urine levels of 9-hydroxyfluorene, a fluorene metabolite, and 2-hydroxyphenanthrene, a phenanthrene metabolite, were higher in our $\mathrm{AD}$ patients compared to the HCs, although a statistical significance was not reached after 
Bonferroni correction and their correlations with disease activity were very weak. The AD patients were older than the HCs, however age was not strongly correlated with urine levels of 9-hydroxyfluorene or 2-hydroxyphenanthrene (Spearman's correlation coefficient with 1000 bootstraps: $0.10,95 \%$ CI $-0.22,0.43$ and $0.27,95 \%$ CI $-0.03,0.57$, respectively, data not shown). We do not believe that the difference in age influenced our results.

PAHs include a constellation of organic chemicals, and their relationship with carcinogenesis has been well established based on epidemiological and experimental studies. ${ }^{20}$ Several studies have linked ambient PAH exposure to the pathogenesis of allergy. Schober et al. demonstrated that both U.S. Environmental Protection Agency (EPA) priority PAHs and PAH-containing airborne particulate matter or diesel exhaust extracts could synergistically enhance recombinant Bet $\mathrm{v} 1$ stimulation of basophils in birch pollen-allergic patients. ${ }^{21,22}$ Takenaka et al. found that PAH extracts from diesel exhaust enhanced IgE production from purified human donor B cells after stimulation with IL-4 and CD40 monoclonal antibodies. ${ }^{1}$ Tsien et al. also showed that PAH extracts from diesel exhaust could stimulate IgE production in the 2C4/ F3 cell line, an Epstein-Barr virus-transformed human B cell line. ${ }^{23}$ For specific PAHs, phenanthrene has been reported to significantly enhance IL-4/IL-8 secretion and histamine release from purified basophils without antigen stimulation in birch pollen-allergic patients. ${ }^{23,24}$ Phenanthrene has also been shown to dose-dependently enhance IgE production by human $\mathrm{B}$ cells. ${ }^{23}$ In addition, phenanthrene treatment has been shown to impair Treg function and even convert Treg into a Th2 phenotype through an epigenetic mechanism. ${ }^{24}$ Epidemiological studies also provided clues. Miller et al. reported a positive association between urine metabolites of fluorene and phenanthrene and anti-mouse and anti-cat IgE levels in a birth cohort of New York City children. ${ }^{16}$ Another study used the US National Health and Nutrition Examination Surveys of 2001-2008 and 2011-2012 to investigate the association between urinary PAH metabolites and asthma-related symptoms in children. ${ }^{2}$ The authors found an association between urinary metabolites of phenanthrene, but not fluorene, and asthma-related symptoms. In another case-control study of 195 Saudi children, serum levels of fluorene, but not phenanthrene, were higher in asthmatics than in non-ashtmatics. ${ }^{25}$ Taken together, our results are consistent with these previous studies. In particular, the biological plausibility regarding the effect of phenanthrene on allergic response is supported by several laboratory studies.

Previous studies have suggested the role of $A h R$ in the pathogenesis of $\mathrm{AD}$. Kim et al. found an increased $\mathrm{AhR}$ mRNA expression in lesional skin of AD patients compared with normal skin of HCs. ${ }^{26}$ Transgenic mice overexpressing AhR have also been shown to develop inflammatory skin lesions which resemble AD. ${ }^{8,27}$ In addition, some studies have indicated that AhR signaling is an important mechanism mediating the biological effect of $\mathrm{PAH}{ }^{3}$ In our study, PBMC expression levels of $\mathrm{AhR}$ were weakly correlated with both serum IgE and SCORAD index in our AD patients. However, PBMCs from the AD patients did not have a higher expression of AhR than the HCs. Nevertheless, we did not measure skin AhR expression, which may be more closely related to the pathology of AD.

Several studies have investigated perturbations in blood levels of cytokines in $\mathrm{AD}$ patients. In these studies, increased blood levels of IL-4, IL-5, IL-17 and IL-23 and decreased blood levels of IFN- $\gamma$ and IL-10 were found in AD children compared with HCs. ${ }^{28,29}$ Blood cytokine profile in adult AD patients is somewhat different from children with AD. ${ }^{30,31}$ In Vakirlis et al's study of 21 adult AD patients with active disease, decreased patient serum levels of IL-4, IL-6, IL-10 and IFN- $\gamma$ were demonstrated compared with $\mathrm{HCs}^{30}$ In line with their finding, we observed decreased mRNA expression levels of IFN- $\gamma$ in the PBMCs of the adult AD patients. In addition, we observed lower plasma levels of IL-5 and IL-23 in adult $\mathrm{AD}$ patients, which is discrepant from children with $\mathrm{AD} .^{36,37}$ We also examined the correlations between plasma cytokine levels/PBMC cytokine expression levels and serum IgE/ SCORAD index. Interferon- $\gamma$ is a Th1 cytokine and its negative correlation with serum IgE is no surprise. IL-23, though a Th17 cytokine, has been demonstrated to promote GATA3 expression and Th2 cytokine expression. ${ }^{32}$ This may explain our observation of a moderate association between plasma levels of IL-23 and serum IgE levels. In Vakirlis et al.s study, serum TNF levels correlated with SCORAD in adult AD patients with active disease, ${ }^{33}$ which is compatible with our observation of a weak correlation between plasma levels of TNF- $\alpha$ and SCORAD. We also found a moderate correlation between plasma levels of IL-22 and SCORAD. This is accordance with recent findings in support of a pivotal role of IL22 in $\mathrm{AD}$ pathogenesis, such as elicitation of an inflammatory response, epidermal hyperplasia and disruption of skin barrier. $^{34}$

There are several limitations to this study. First, the small number of sample size limits the power of the study. In particular, we tried to recruit as many healthy controls as we could, but the requirement of no allergic diseases and negative skin prick test to major allergens is hard to meet. Due to the same reason, we did not recruit age- and sex-matched controls. Nevertheless, plasma cytokine levels, PBMC expression levels, and urine $\mathrm{PAH}$ metabolite concentrations were not strongly associated with either age or sex (data not shown). Second, our $\mathrm{AD}$ patients were not newly diagnosed, and a majority of them were taking systemic immunomodulators. We did not ask them to hold medications due to ethical reasons. This may have influenced some of the study results, especially those in regard to cytokines. However, plasma cytokine levels, PBMC expression levels, and urine PAH metabolite concentrations were not different between $\mathrm{AD}$ patients who took or not took systemic immunomodulators (data not shown), except for a lower PBMC IFN- $\gamma$ expression levels among those patients who took systemic immunomodulators when compared with those who did not (relative mRNA expression level: $9.0 \times 10^{-5}$ vs. $\left.2.4 \times 10^{-4}\right)$. Moreover, our results were in part in line with previous studies of adult AD patients. Third, comorbidities such as allergic rhinitis and asthma may partly account for the associations between urine levels of PAH metabolites and $\mathrm{AD}$, although 9 (39\%) of $23 \mathrm{AD}$ patients had neither allergic rhinitis nor asthma. Fourth, some studies have implied a synergistic mechanism in PAH toxicity. ${ }^{33,35}$ 
Nevertheless, our sample size was not sufficient to analyze interactions between different PAH compounds. Finally, it is not possible to determine any causal relationship based on our results due to the cross-sectional study design.

\section{Conclusion}

In conclusion, our results demonstrated that urine metabolites of some PAHs, including fluorene and phenanthrene, were elevated in our adult $\mathrm{AD}$ patients. This indicates the potential effect of PAHs on the pathogenesis of $\mathrm{AD}$.

\section{Acknowledgments}

We sincerely thank the Biostatistics Task Force of Taichung Veterans General Hospital, Taichung, Taiwan, for its assistance with the statistical analysis.

\section{Conflicts of interest}

The authors declare no conflict of interest. This study was supported by a grant from Taichung Veterans General Hospital (TCVGH-1053802B), Taichung, Taiwan, Republic of China, and a grant from Taichung Veterans General Hospital and National Health Research Institutes (TCVGH-NHRI10903).

\section{Author contributions}

KTT and YHC conceived of the presented idea. PAC, MRL and MFL carried out the experiments. KTT and YHC contributed to the interpretation of the results. KTT and YHC took the lead in writing the manuscript. All authors have read and approved the final manuscript

\section{References}

1. Takenaka H, Zhang K, Diaz-Sanchez D, Tsien A, Saxon A. Enhanced human IgE production results from exposure to the aromatic hydrocarbons from diesel exhaust: direct effects on B-cell IgE production. J Allergy Clin Immunol. 1995;95(1 Pt 1):103-15.

2. Liu $\mathrm{H}, \mathrm{Xu} \mathrm{C}$, Jiang $\mathrm{ZY}, \mathrm{Gu} \mathrm{A}$. Association of polycyclic aromatic hydrocarbons and asthma among children 6-19 years: NHANES 2001-2008 and NHANES 2011-2012. Respir Med. 2016;110:20-7.

3. Denison MS, Pandini A, Nagy SR, Baldwin EP, Bonati L. Ligand binding and activation of the Ah receptor. Chem Biol Interact. 2002;141(1-2): 3-24.

4. Sibilano R, Pucillo CE, Gri G. Allergic responses and aryl hydrocarbon receptor novel pathway of mast cell activation. Mol Immunol. 2015; 63(1):69-73.

5. Stevens EA, Mezrich JD, Bradfield CA. The aryl hydrocarbon receptor: a perspective on potential roles in the immune system. Immunology. 2009;127(3):299-311.

6. Wei P, Hu GH, Kang HY, Yao HB, Kou W, Liu H, et al. Increased aryl hydrocarbon receptor expression in patients with allergic rhinitis. QJM. 2014;107(2):107-13.

7. Zhu J, Cao Y, Li K, Wang Z, Zuo P, Xiong W, et al. Increased expression of aryl hydrocarbon receptor and interleukin 22 in patients with allergic asthma. Asian Pac J Allergy Immunol. 2011;29(3):266-72.

8. Hidaka T, Ogawa E, Kobayashi EH, Suzuki T, Funayama R, Nagashima T, et al. The aryl hydrocarbon receptor AhR links atopic dermatitis and air pollution via induction of the neurotrophic factor artemin. Nat Immunol. 2017;18(1):64-73.

9. Ahn K. The role of air pollutants in atopic dermatitis. J Allergy Clin Immunol. 2014;134(5):993-9; discussion 1000.

10. Morgenstern V, Zutavern A, Cyrys J, Brockow I, Koletzko S, Kramer U, et al. Atopic diseases, allergic sensitization, and exposure to traffic-related air pollution in children. Am J Respir Crit Care Med. 2008;177(12): 1331-7.
11. Tang $\mathrm{KT}, \mathrm{Ku} \mathrm{KC}$, Chen DY, Lin $\mathrm{CH}$, Tsuang BJ, Chen YH. Adult atopic dermatitis and exposure to air pollutants-a nationwide population-based study. Ann Allergy Asthma Immunol. 2017;118(3):351-5.

12. Hanifin JM RG. Disgnostic features of atopic dermatitis. Acta Dermato -Venereologica. 1980(92):Suppl. 44-7.

13. Lee MF, Wang NM, Liu SW, Lin SJ, Chen YH. Induction of interleukin 8 by American cockroach allergens from human airway epithelial cells via extracellular signal regulatory kinase and jun N-terminal kinase but not p38 mitogen-activated protein kinase. Ann Allergy Asthma Immunol. 2010;105(3):234-40.

14. Chen YH, Lee MF, Tsai JJ, Wu HJ, Hwang GY. Specific IgE and IgG responses and cytokine profile in subjects with allergic reactions to biting midge Forcipomyia taiwana. Int Arch Allergy Immunol. 2009; 150(1):66-74

15. Severity scoring of atopic dermatitis: the SCORAD index. Consensus Report of the European Task Force on Atopic Dermatitis. Dermatology. 1993;186(1):23-31.

16. Miller RL, Garfinkel R, Lendor C, Hoepner L, Li Z, Romanoff L, et al. Polycyclic aromatic hydrocarbon metabolite levels and pediatric allergy and asthma in an inner-city cohort. Pediatr Allergy Immunol. 2010;21 (2 Pt 1):260-7.

17. Li Z, Sandau CD, Romanoff LC, Caudill SP, Sjodin A, Needham LL, et al. Concentration and profile of 22 urinary polycyclic aromatic hydrocarbon metabolites in the US population. Environ Res. 2008;107(3):320-31.

18. Zhu L, $\mathrm{Xu} \mathrm{H}$. Magnetic graphene oxide as adsorbent for the determination of polycyclic aromatic hydrocarbon metabolites in human urine. J Sep Sci. 2014;37(18):2591-8.

19. Whiteley J, Emir B, Seitzman R, Makinson G. The Burden of Atopic Dermatitis in U.S. Adults: Results from the 2013 National Health and Wellness Survey. Curr Med Res Opin. 2016:1-32.

20. Armstrong B, Hutchinson E, Unwin J, Fletcher T. Lung cancer risk after exposure to polycyclic aromatic hydrocarbons: a review and meta-analysis. Environ Health Perspect. 2004;112(9):970-8.

21. Schober W, Lubitz S, Belloni B, Gebauer G, Lintelmann J, Matuschek G, et al. Environmental polycyclic aromatic hydrocarbons (PAHs) enhance allergic inflammation by acting on human basophils. Inhal Toxicol. 2007;19 Suppl 1:151-6.

22. Lubitz S, Schober W, Pusch G, Effner R, Klopp N, Behrendt H, et al Polycyclic aromatic hydrocarbons from diesel emissions exert proallergic effects in birch pollen allergic individuals through enhanced mediator release from basophils. Environ Toxicol. 2010;25(2):188-97.

23. Tsien A, Diaz-Sanchez D, Ma J, Saxon A. The organic component of diesel exhaust particles and phenanthrene, a major polyaromatic hydrocarbon constituent, enhances IgE production by IgE-secreting EBV-transformed human B cells in vitro. Toxicol Appl Pharmacol. 1997; 142(2):256-63.

24. Liu J, Zhang L, Winterroth LC, Garcia M, Weiman S, Wong JW, et al. Epigenetically mediated pathogenic effects of phenanthrene on regulatory T cells. J Toxicol. 2013;2013:967029.

25. Al-Daghri NM, Alokail MS, Abd-Alrahman SH, Draz HM, Yakout SM, Clerici M. Polycyclic aromatic hydrocarbon exposure and pediatric asthma in children: a case-control study. Environ Health. 2013;12:1.

26. Kim HO, Kim JH, Chung BY, Choi MG, Park CW. Increased expression of the aryl hydrocarbon receptor in patients with chronic inflammatory skin diseases. Exp Dermatol. 2014;23(4):278-81.

27. Tauchi M, Hida A, Negishi T, Katsuoka F, Noda S, Mimura J, et al Constitutive expression of aryl hydrocarbon receptor in keratinocytes causes inflammatory skin lesions. Mol Cell Biol. 2005;25(21):9360-8.

28. Leonardi S, Cuppari C, Manti S, Filippelli M, Parisi GF, Borgia F, et al. Serum interleukin 17, interleukin 23, and interleukin 10 values in children with atopic eczema/dermatitis syndrome (AEDS): association with clinical severity and phenotype. Allergy Asthma Proc. 2015;36(1): 74-81.

29. Noh GW, Lee KY. Blood eosinophils and serum IgE as predictors for prognosis of interferon-gamma therapy in atopic dermatitis. Allergy. 1998;53(12):1202-7.

30. Vakirlis E, Lazaridou E, Tzellos TG, Gerou S, Chatzidimitriou D, Ioannides D. Investigation of cytokine levels and their association with SCORAD index in adults with acute atopic dermatitis. J Eur Acad Dermatol Venereol. 2011;25(4):409-16.

31. Nygaard U, Hvid M, Johansen C, Buchner M, Folster-Holst R, Deleuran M, et al. TSLP, IL-31, IL-33 and sST2 are new biomarkers in endophenotypic profiling of adult and childhood atopic dermatitis. J Eur Acad Dermatol Venereol. 2016;30(11):1930-8. 
32. Peng J, Yang XO, Chang SH, Yang J, Dong C. IL-23 signaling enhances Th2 polarization and regulates allergic airway inflammation. Cell Res. 2010;20(1):62-71.

33. Li Q, Lauer FT, Liu KJ, Hudson LG, Burchiel SW. Low-dose synergistic immunosuppression of T-dependent antibody responses by polycyclic aromatic hydrocarbons and arsenic in C57BL/6J murine spleen cells. Toxicol Appl Pharmacol. 2010;245(3):344-51.

34. Brunner PM, Pavel AB, Khattri S, Leonard A, Malik K, Rose S, et al. Baseline IL-22 expression in patients with atopic dermatitis stratifies tissue responses to fezakinumab. J Allergy Clin Immunol. 2019;143(1): $142-54$.

35. Jayasundara N, Van Tiem Garner L, Meyer JN, Erwin KN, Di Giulio RT. AHR2-Mediated transcriptomic responses underlying the synergistic cardiac developmental toxicity of PAHs. Toxicol Sci. 2015;143(2):469-81.

\section{Appendix}

Table S1. The relative recoveries and LOD values of 16 urine PAH metabolites using MGCB-based gas chromatographymass spectrophotometer.

\begin{tabular}{|lcc|}
\hline \multicolumn{1}{|c}{ Compounds } & LOD (pg/ml) & Relative recovery (\%) \\
\hline 1-hydroxynaphthalene & 3 & 103.1 \\
\hline 2-hydroxynaphthalene & 59 & 93.8 \\
\hline 2-hydroxyfluorene & 10 & 117.8 \\
\hline 3-hydroxyfluorene & 1 & 105.8 \\
\hline 9-hydroxyfluorene & 21 & 96.4 \\
\hline 1-hydroxyphenanthrene & 1 & 111.0 \\
\hline 2-hydroxyphenanthrene & 1 & 94.9 \\
\hline 3-hydroxyphenanthrene & 3 & 99.4 \\
\hline 4-hydroxyphenanthrene & 1 & 86.7 \\
\hline 9-hydroxyphenanthrene & 0.2 & 105.2 \\
\hline 1-hydroxypyrene & 1 & 96.7 \\
\hline 9-hydroxybenz[a]anthracene & 2 & 100.3 \\
\hline 2-hydroxychrysene & 2 & 102.2 \\
\hline 3-hydroxychrysene & 2 & 100.3 \\
\hline 6-hydroxychryseneh & 1 & 1.3 \\
\hline
\end{tabular}

LOD, limit of detection; MGCB, magnetic graphitized carbon black; PAH, polycyclic aromatic hydrocarbon. 